\title{
Synchronous multifocal necrotizing fasciitis prognostic factors: a retrospective case series study in a single center
}

\author{
Ching-Yu Lee ${ }^{1,3,5} \cdot$ Yen-Yao $\mathrm{Li}^{1} \cdot$ Tsan-Wen Huang ${ }^{1,5} \cdot$ Tsung-Yu Huang $^{2}$ • \\ Wei-Hsiu Hsu ${ }^{1,3,5} \cdot$ Yao-Hung Tsai $^{1} \cdot$ Jou-Chen Huang ${ }^{4}$ Kuo-Chin Huang ${ }^{1,3}$
}

Received: 17 February 2016 / Accepted: 28 July 2016 / Published online: 24 October 2016

(c) The Author(s) 2016. This article is published with open access at Springerlink.com

\begin{abstract}
Purpose No reports have been published on synchronous multifocal necrotizing fasciitis (SMNF), a multifocal presence of necrotizing fasciitis in different extremities. We evaluated the clinical characteristics and outcomes of SMNF.

Methods Eighteen patients (14 men, 4 women; mean age: 59 years) diagnosed with SMNF of the extremities between January 2004 to December 2012 were enrolled and evaluated.

Results Vibrio species were the most commonly (78\%; $n=14)$ isolated; others were two cases (11\%) of Aeromonas spp., one case $(6 \%)$ of group A $\beta$-hemolytic streptococcus, and one case of coagulase-negative staphylococcus. SMNF was in the bilateral lower limbs $(72 \% ; n=13)$, bilateral upper limbs $(17 \% ; n=3)$, and one patient with one upper and one lower limb (11\%). Non-surviving patients had more bilateral lower limb involvement and thrombocytopenia.

Conclusions Most patients with SMNF were male and had bilateral lower limb and marine Gram-negative bacteria involvement. The mortality of SMNF remained extremely
\end{abstract}

Kuo-Chin Huang

orthoejaca@gmail.com

1 Department of Orthopedic Surgery, Chang Gung Memorial Hospital, No. 6, West Sec., Jiapu Road, Puzi City, Chiayi 613, Taiwan

2 Division of Infectious Diseases, Department of Internal Medicine, Chang Gung Memorial Hospital, Chiayi, Taiwan

3 Graduate Institute of Clinical Medical Sciences, College of Medicine, Chang Gung University, Taoyuan, Taiwan

4 Department of Ophthalmology, Chang Gung Memorial Hospital, Chiayi, Taiwan

5 College of Medicine, Chang Gung University, Taoyuan, Taiwan high in patients with involvement of bilateral lower limb and initial thrombocytopenia.

Keywords Synchronous $\cdot$ Multifocal $\cdot$ Necrotizing fasciitis $\cdot$ Prognostic factors

\begin{abstract}
Abbreviations
SMNF Synchronous multifocal necrotizing fasciitis

NF Necrotizing fasciitis
\end{abstract}

\section{Introduction}

Necrotizing fasciitis (NF) is an uncommon deep soft tissue infection characterized by a rapidly spreading necrosis of superficial fascia and subcutaneous tissue [1]. Although typical NF involves primarily a single site, some recent studies report the concurrent involvement of multiple sites [2-4]. Some reports $[2,5,6]$ incidentally indicate that multifocal necrotizing fasciitis leads to a higher mortality rate than does monofocal NF. We found no reports that focused primarily on synchronous multifocal necrotizing fasciitis (SMNF). Thus, we evaluated the clinical characteristics and outcomes of SMNF.

\section{Patients and methods}

\section{Patients}

We reviewed the records of patients diagnosed with and treated for SMNF at our hospital from January 2004 to December 2012. SMNF was defined as a multifocal presence of necrotizing fasciitis (NF) in different extremities at the initial visit. It was defined using surgical findings: the 
presence of grayish necrotic skin, subcutaneous fat and fascia, no resistance of normally adherent fascia to digital blunt dissection, and a purulent discharge resembling foulsmelling dishwater. Histopathological tissue specimens were obtained to confirm the diagnoses. Exclusion criteria were: (1) monofocal necrotizing fasciitis, (2) central necrotizing fasciitis (involvement of trunk or perineum), (3) a negative microbiological culture of the infected specimen, (4) concomitant chronic infections (e.g., osteomyelitis), and (5) a preexisting chronic wound (e.g., diabetic foot ulcer and decubitus ulcer).

\section{Treatment protocol}

The treatment protocol included adequate antibiotic therapy and prompt radical debridement. All patients underwent emergency surgery within $1 \mathrm{~h}$ of admission when necrotizing fasciitis was suspected. Patients with multiple comorbidities, or an unstable hemodynamic status (systolic blood pressure $<90 \mathrm{mmHg}$ or mean arterial pressure $<65 \mathrm{mmHg}$ ) were transferred to the intensive care unit for postoperative intensive care. Surgical debridement was done every other day if progressive necrotic changes combined with a deteriorating clinical presentation. Initial empiric broad-spectrum antibiotics were administered and adjusted based on blood and tissue culture results. Soft tissue reconstruction was done until the infected necrotic tissue was controlled and stabilized.

\section{Data analysis}

Patient characteristics, presenting signs and symptoms, location of infection, underlying comorbidities, laboratory findings at the time of admission, bacteriologic results, and final outcomes in all patients were reviewed using the electronic database at our hospital. In regard to laboratory analysis, leukocytosis was defined as a white blood cell count greater than $12,000 / \mu 1$, and thrombocytopenia was defined as a platelet count lower than $150,000 / \mu$ l of blood. To assess clinical outcomes after antibiotic therapy and surgical debridement, mortality was defined as death because of progressive sepsis or medical complications within 12 months after surgery. To evaluate the predictive factors of mortality in SMNF, the variables were analyzed between survivors and non-survivors.

\section{Statistical methods}

Univariate analysis was used to determine factors associated with the survivors and non-survivors. An independent Student's $t$ test was used for numerical data. A $\chi^{2}$ analysis or a Fisher's exact test was used for categorical data. Descriptive data are presented as the mean with standard deviation for quantitative variables and as frequency for categorical variables. Statistical significance was set at $p<0.05$. SPSS 12.0 for Windows (SPSS Institute, Chicago, IL, USA) was used for all statistical analyses.

\section{Results}

\section{Patient characteristics}

We reviewed 401 patients diagnosed with NF at our hospital from January 2004 to December 2012. We excluded 383 patients: 150 with monofocal NF of the extremities, 88 with NF involving the trunk, 128 with concomitant chronic osteomyelitis, surgical wound infection, chronic diabetic or decubitus ulcer, and 17 with culture-negative NF. Eighteen (5\%) patients (14 men, 4 women; mean age 59 years; age range 38-79 years) (Table 1) were diagnosed with SMNF of the extremities. The survivors were followed up for a minimum of 1 year (mean 16 months; range 12-24 months). Vibrio species [14 (78\%) cases] were the most common. Others were Aeromonas spp. [2 (11\%) cases], group A $\beta$-hemolytic streptococcus [1 (6\%)], and coagulase-negative staphylococcus [1 (6\%)]. Twelve (67\%) of the 18 enrolled patients presented in shock on admission and required aggressive resuscitation. The extremity distribution of NF included the bilateral lower limbs (72\%), bilateral upper limbs (17\%), and one patient with one upper and one lower limb (11\%) (Table 2). Fourteen patients immediately underwent a fasciotomy and debridement, and four patients (22\%) had an initial amputation. Twelve patients with SMNF died: ten patients died of the uncontrolled original infection, one patient died of complicated pneumonia and a fungal urinary tract infection with fungemia, and one patient died of comorbidities [liver cirrhosis (Child-Pugh Class C) and upper gastrointestinal bleeding] within 4 months after hospital discharge.

\section{Patient characteristics compared}

Almost all of the non-survivors developed NF of the bilateral lower limbs, except for one non-survivor with affected bilateral upper limbs; all of the survivors had NF of the bilateral upper limbs $(p=0.005)$ (Table 3). Differences in age, gender, comorbidities, and duration of symptoms were not significant.

\section{Laboratory data compared}

Survivors had a higher rate of leukocytosis than did nonsurvivors ( 83 vs. $17 \%, p=0.013$ ) (Table 4 ). The prevalence of thrombocytopenia was higher in non-survivors than in survivors ( 92 vs. $17 \%, p=0.004$ ). Bacteremia occurred in 
Table 1 Patient characteristics

\begin{tabular}{|c|c|c|c|c|c|c|c|}
\hline PT \# & Age (years) & Sex & Occupation & Microbe & Comorbidity & $\mathrm{S} / \mathrm{S}$ at first visit & Exposure history \\
\hline 1 & 38 & Male & Fisherman & V. vulnificus & LC, AA & $\mathrm{S}, \mathrm{H}, \mathrm{P}$ & Seawater \\
\hline 2 & 38 & Male & Farmer & $\beta$-hem. strep. & LC, HBV, HCV, AA & $\mathrm{S}, \mathrm{F}, \mathrm{P}$ & NA \\
\hline 3 & 58 & Male & Fisherman & V. vulnificus & NA & $\mathrm{F}, \mathrm{H}, \mathrm{P}$ & Seawater \\
\hline 4 & 70 & Male & Fisherman & V. vulnificus & $\mathrm{DM}$ & $\mathrm{S}, \mathrm{H}, \mathrm{P}$ & Seawater \\
\hline 5 & 76 & Male & Fisherman & CoNS & $\mathrm{AA}, \mathrm{COPD}$ & $\mathrm{P}$ & NA \\
\hline 6 & 59 & Male & Plasterer & V. vulnificus & $\mathrm{AA}, \mathrm{AR}, \mathrm{IE}$ & $\mathrm{P}$ & Fish \\
\hline 7 & 60 & Male & Fisherman & V. vulnificus & LC, AA, ESRD & $\mathrm{S}, \mathrm{H}, \mathrm{P}$ & Seawater \\
\hline 8 & 79 & Male & Farmer & V. vulnificus & ESRD, gout & $\mathrm{S}, \mathrm{H}, \mathrm{P}$ & Farmland \\
\hline 9 & 52 & Female & NA & V. vulnificus & LC, HBV, HCV, HCC & $\mathrm{S}, \mathrm{F}, \mathrm{P}$ & NA \\
\hline 10 & 57 & Male & Plasterer & V. vulnificus & $\mathrm{HCV}, \mathrm{DM}$ & $\mathrm{S}, \mathrm{F}, \mathrm{P}$ & Oyster \\
\hline 11 & 63 & Female & Barber & V. vulnificus & $\mathrm{LC}, \mathrm{HCV}$ & $\mathrm{S}, \mathrm{F}, \mathrm{H}, \mathrm{P}$ & NA \\
\hline 13 & 51 & Male & NA & V. cholerae & LC, HBV, ESRD, AA & $\mathrm{S}, \mathrm{F}, \mathrm{H}, \mathrm{P}$ & Seafood \\
\hline 14 & 59 & Male & Farmer & $\begin{array}{l}\text { A. sobria } \\
\text { Klep. pneumoniae }\end{array}$ & LC, HCC, AA & $\mathrm{S}, \mathrm{P}$ & NA \\
\hline 15 & 53 & Male & Plasterer & V. vulnificus & LC, AA & $\mathrm{H}, \mathrm{P}$ & NA \\
\hline 16 & 79 & Male & Farmer & V. vulnificus & DM, AA, AR & $\mathrm{S}, \mathrm{F}, \mathrm{H}, \mathrm{P}$ & NA \\
\hline 17 & 68 & Female & Farmer & A. hydrophila & Steroid abuse & $\mathrm{S}, \mathrm{H}, \mathrm{P}$ & Bamboo stabbing \\
\hline 18 & 64 & Female & Barber & V. vulnificus & $\mathrm{HCV}, \mathrm{DM}, \mathrm{AR}$ & $\mathrm{S}, \mathrm{F}, \mathrm{H}, \mathrm{P}$ & NA \\
\hline
\end{tabular}

$P T$ patient, $S / S$ signs and symptoms, V. Vibrio, CoNS coagulase-negative staphylococci, A. Aeromonas, $\beta$-hem. Strep. group A $\beta$-hemolytic streptococcus, Klep. Klebsiella, $A A$ alcohol abuse, $L C$ liver cirrhosis, $H B V$ hepatitis B virus, $H C V$ hepatitis $\mathrm{C}$ virus, $H C C$ hepatic cell carcinoma, $D M$ diabetes mellitus, $C O P D$ chronic obstructive pulmonary disease, ESRD end-stage renal disease, $A R$ aortic regurgitation, $S$ shock, $F$ fever, $H$ hemorrhagic bullae, $P$ limb pain, $N A$ not available

Table 2 Additional patient characteristics

\begin{tabular}{llllll}
\hline PT \# & Affected limbs & Onset day & Antibiotics & Initial surgery & Outcome \\
\hline 1 & RF, LF & 3 & Ceftriaxone & FD & Survival \\
2 & RA, LT & 2 & Ceftriaxone & FD & Survival \\
3 & RH, LH & 1 & Imipenem \& cilastatin sodium, MSD & FD & Survival \\
4 & RH, RH & 2 & Ceftriaxone & FD & Survival \\
5 & RA, LA & 5 & Ceftriaxone & FD & Survival \\
6 & RH, LL & 1 & Ceftriaxone & AMP, FD & Survival \\
7 & RL, LL & 1.5 & Ceftriaxone & FD & Death \\
8 & RL, LL & 1 & Imipenem \& cilastatin sodium, MSD & FD & Death \\
9 & RL, LL, LH & 1 & Ceftriaxone & FD & Death \\
10 & RL, LL & 1 & Ceftriaxone & Bil. AMP & Death \\
11 & RL, LL & 1 & Ceftriaxone & FD & Death \\
12 & RL, LL & 1 & Ceftazidime & Bil. AMP & Death \\
13 & RL, LL & 1 & Ceftriaxone & FD & Death \\
14 & RL, LL & 1 & Ceftriaxone & FD & Death \\
15 & RL, LF & 1 & Ceftriaxone & FD & Death \\
16 & RL, LL & 1 & Ceftazidime & FD & Death \\
17 & RL, LL & 1 & Ceftriaxone & FD & Death \\
18 & RH, LH & 1 & Ceftriaxone & Bil. AMP & Death \\
\hline
\end{tabular}

$P T$ patient, $R A$ right arm, $L A$ left arm, $R H$ right hand, $L H$ left hand, $R L$ right leg, $L L$ left leg, $R F$ right foot, $L F$ left foot, $F D$ fasciotomy and debridement, $A M P$ amputation, Bil. AMP bilateral amputation 
Table 3 Comparison of patient characteristics

\begin{tabular}{llll}
\hline Characteristic & Survivors $(n=6)$ & Non-survivors $(n=12)$ & $p$ \\
\hline Age (years) & $57 \pm 16$ & $61 \pm 10$ & 0.486 \\
Males & $6(100)$ & $8(67)$ & 0.245 \\
Duration of symptoms (days) & $2.3 \pm 1.5$ & $1 \pm 0.1$ & 0.09 \\
Extremities affected & & & $0.005^{*}$ \\
Bilateral upper & $3(50)$ & $1(8)$ & \\
Bilateral lower & $1(17)$ & $11(92)$ & \\
Both upper and lower & $2(33)$ & 0 & 1 \\
Comorbidity & & & 0.515 \\
Diabetes mellitus & $1(17)$ & $2(17)$ & 0.141 \\
ESRD & 0 & $3(25)$ & 0.31 \\
CLD & $2(33)$ & $9(75)$ & 0.152 \\
Liver cirrhosis & $2(33)$ & $7(58)$ & \\
Hepatitis B virus or hepatitis C virus & $1(17)$ & $6(50)$ & \\
\hline
\end{tabular}

Data are mean \pm standard deviation or number (\%)

$C L D$ chronic liver diseases: liver cirrhosis, hepatitis $\mathrm{B}$ virus, or hepatitis $\mathrm{C}$ virus

$* p<0.05$
Table 4 Comparison of laboratory data

\begin{tabular}{llll}
\hline Laboratory data & Survivors $(n=6)$ & $\begin{array}{l}\text { Non-survivors } \\
(n=12)\end{array}$ & $p$ \\
\hline $\begin{array}{l}\text { Leukocytosis } \\
\quad \geq 12,000 / \mu \mathrm{L})\end{array}$ & $5(83)$ & $2(17)$ & $0.013^{*}$ \\
$\begin{array}{l}\text { Thrombocytopenia } \\
\text { Hemoglobin (g/dL) }\end{array}$ & $1(17)$ & $11(92)$ & $0.004^{*}$ \\
$\begin{array}{l}\text { C-reactive protein } \\
(\mathrm{mg} / \mathrm{dL})\end{array}$ & $198.0 \pm 119$ & $13 \pm 1.6$ & 0.229 \\
$\begin{array}{l}\text { Albumin }(\mathrm{g} / \mathrm{dL}) \\
\text { Bacteremia }\end{array}$ & $2.4 \pm 0.5$ & $61 \pm 40$ & 0.061 \\
\hline
\end{tabular}

$* p<0.05$

$50 \%$ of survivors and in $83 \%$ of non-survivors $(p=0.268)$. The levels of serum hemoglobin, C-reactive protein, and albumin were not significantly different between the two groups.

\section{Bacterial cultures compared}

Gram-negative bacteria were predominantly isolated in both groups, especially Vibrio vulnificus. There was no significant difference in bacterial species between the groups (Table 5).

\section{Discussion}

This is the first report of a case series of SMNF and analysis of its predictive factors for mortality. In the current study, SMNF accounted for $5 \%$ of NF. The main
Table 5 Comparison of bacterial cultures from tissue specimens

\begin{tabular}{llll}
\hline Bacterial culture & $\begin{array}{l}\text { Survivors } \\
(n=6)\end{array}$ & $\begin{array}{l}\text { Non-survivors } \\
(n=12)\end{array}$ & $p$ \\
\hline $\begin{array}{l}\text { Gram-positive bacteria } \\
\text { Gram-negative bacteria }\end{array}$ & $2(33)$ & 0 & 0.098 \\
$\begin{array}{l}\text { Group A } \beta \text {-hemolytic } \\
\text { strep. }\end{array}$ & $1(17)$ & 0 & \\
$\begin{array}{l}\text { Coagulase-negative } \\
\text { staph. }\end{array}$ & $1(17)$ & 0 & \\
$\begin{array}{l}\text { Vibrio vulnificus } \\
\text { Vibrio cholerae }\end{array}$ & $4(67)$ & $9(75)$ & \\
Aeromonas sobria & 0 & $1(8)$ & \\
Aeromonas hydrophila & 0 & $1(8)$ & $1(8)$ \\
Klep. pneumoniae & 0 & $1(8)$ &
\end{tabular}

strep. streptococcus, staph. staphylococcus, Klep. Klebsiella

characteristics of our patients with SMNF were male sex, lower limb involvement, and marine Gram-negative bacterial infection. The incidence of SMNF in noncontiguous sites is not clear in the literature. Park et al. [5], in a retrospective case review of 217 patients with NF in the coastal area of South Korea, reported that at least 73 (34\%) patients had noncontiguous multifocal involvement with highly frequent isolation of Gram-negative marine bacteria. El-Khani et al. [2], in a case report and systematic review of 33 cases of multifocal NF, reported that most patients were male, that their lower limbs were involved, and that there were 18 Gram-positive bacteria, 6 Gram-negative bacteria, 5 anaerobic bacteria, 1 yeast, and 4 polymicrobial isolates in the microbiologic cultures. Similar to the findings of Park et al. [5], most of our cases 
were classified as type III NF (infection by monomicrobial pathogen, usually Gram-negative bacteria). Moreover, in $89 \%$ of our patients with SMNF, marine bacteriaVibrio spp. in $78 \%$ and Aeromonas spp. in 11\%-were most commonly isolated. In contrast, there were $12 \%$ type I NF (infection by polymicrobial bacteria) and 52\% type II (infection by a monomicrobial pathogen, usually Grampositive bacteria) in El-Khani et al. [2]. The different bacteria isolated might be attributable to the different geographical regions and epidemiology of the cases reported [7-9]. Marine bacteria (e.g., Vibrio spp. and Aeromonas spp.) are often found in the warm coastal areas of Asia (e.g., Taiwan, Hong Kong, South Korea, Singapore, and Thailand), the Gulf of Mexico, South America, and Australia [10-12]. Also, NF in patients with chronic liver diseases is usually a monomicrobial infection, caused primarily by Gram-negative bacteria [13,14]. Our hospital is in the Tropic of Cancer in southwestern Taiwan, where many local inhabitants work in fisheries or consume seafood, and where alcoholism, chronic viral hepatitis, and liver cirrhosis are highly prevalent. Therefore, a specific epidemiology, i.e., a high prevalence of chronic liver diseases in a coastal area, would make marine Gram-negative bacteria the main causative pathogens of SMNF.

The overall mortality rate of our patients with SMNF was $67 \%$. Most of the literature focuses only on monofocal NF and reports a cumulative average mortality rate of $34 \%$. The survival rate for NF patients has risen to as high as $85 \%$ as the awareness of monofocal NF has increased and as more-frequent aggressive treatment and adjuvant therapy for the disease have increased. In contrast, multifocal NF remains highly fatal. Park et al. [5] reported that patients with infections in multiple sites had a mortality rate of $62 \%$, significantly higher than the $30 \%$ in patients with a single-site infection. Similarly, Hua et al. [6], in a retrospective single-center cohort study, said that multifocal necrotizing soft tissue infection was an independent risk factor for mortality. SMNF might be caused by rapid metastatic septic embolization or simultaneous multifocal inoculation and the subsequent development of a necrotizing infection. The former implies fulminant septicemia with the hematogenous spread of bacteria, and the latter implies that more than one site has been concomitantly exposed to pathogenic bacteria. Both conditions can lead to overwhelming sepsis. Also, a large area of skin, subcutaneous tissue, fascia, and underlying necrotic destruction of muscle in multiple-site necrotic deep soft tissue will cause extensive complications and a high mortality rate. Like extensive NF that involves a large surface area of the body [15], an immediate fasciotomy and radical removal of necrotic tissue without a misdiagnosis is important when treating SMNF. The treatment protocol should consist of prompt antibiotic therapy, prolonged intensive care, nutritional support, serial surgical
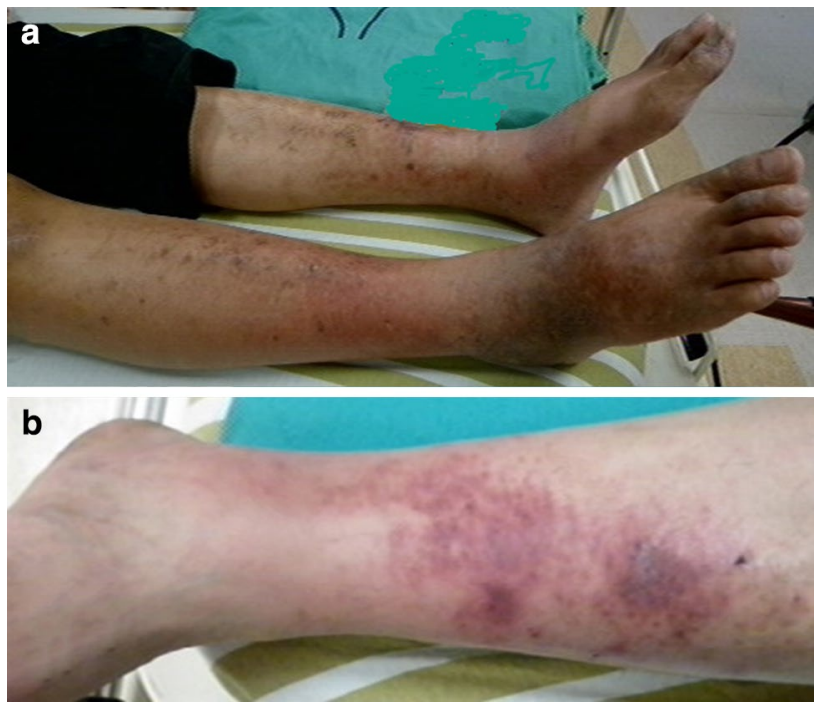

Fig. 1 Extrahepatic cutaneous dermatitis and vasculitis in patient number 13. a Dermatitis with hyperpigmentation-affected bilateral lower limbs; b non-blanching purpura were the main characteristics of vasculitis

debridement, and reconstruction of soft tissue to reduce mortality and morbidity rates.

In the present study, non-survivors had a higher prevalence of involved bilateral lower limbs and thrombocytopenia than did survivors. There is a paucity of reports on the risk factors for SMNF mortality. However, the mortality rate in cases of monofocal NF with upper extremity involvement is not significantly different from that in cases with lower extremity involvement $[16,17]$. El-Khani et al. [2] reported a significantly higher mortality rate in bilaterally affected lower limbs than in bilaterally affected upper limbs (60 vs. 0\%), but the clinical mechanism of mortality related to lower extremity involvement is unclear. In the present study, chronic liver diseases were the most common comorbidities $(61 \%)$ in SMNF, especially in non-survivors $(75 \%)$. Some evidence [18-20] indicates that atherosclerosis and cutaneous vasculitis in the lower limbs were highly associated with chronic liver diseases (e.g., viral hepatitis and alcoholic hepatitis). Also, extrahepatic cutaneous vasculitis [21], primarily of the lower limbs, leads to cutaneous lesions and to an insufficient barrier against bacterial invasions (Fig. 1). Atherosclerosis, vasculitis, and devitalized soft tissue are the results of a poor blood supply, which causes the clinical deterioration of necrotizing deep soft tissue infection [22]. These comorbidities might result in a higher prevalence of involved bilateral lower limbs in patients who die from NF (Fig. 2).

Consistent with our findings for multifocal NF, thrombocytopenia has also been a predictive factor for mortality in monofocal necrotizing deep soft tissue [23, 24]. Physicians should be aware of the grave prognosis for patients 
Fig. 2 Multifocal necrotizing fasciitis 5 years after the onset of extrahepatic cutaneous lesions in patient number 13. a A multifocal presence of necrotizing fasciitis occurred in the bilateral lower limbs; $\mathbf{b}$ hemorrhagic bullae developed on the dorsum of the right foot; c Violet, swollen skin with outof-proportion pain was rapidly progressive in the left leg; $\mathbf{d}$ and e there was no resistance of normally adherent fascia to digital blunt dissection, and there was a purulent discharge resembling foul-smelling dishwater in immediate fasciotomies on the bilateral lower legs
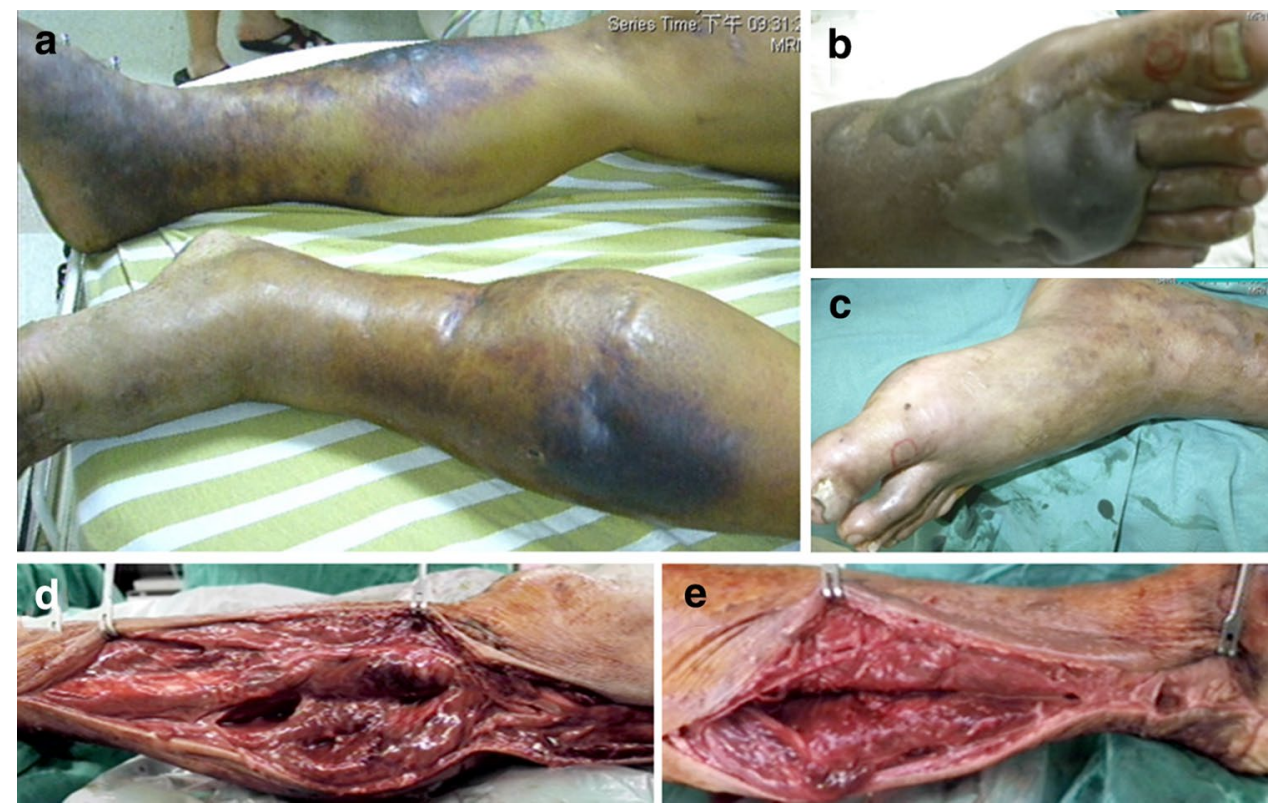

with SMNF of the bilateral lower limbs and who present with thrombocytopenia. Compared with survivors, nonsurvivors tended to have lower, but not significantly different, C-reactive protein (CRP) levels. In contrast, Park et al. [5] reported that the CRP level was one predictor of mortality in NF. Using the CRP level to predict mortality is controversial. Many studies [25, 26] have reported that CRP levels are not significantly different between survivors and non-survivors. Moreover, CRP levels reach peak values between 48 and $72 \mathrm{~h}$ after the onset of bacterial infection [27], and CRP does not precisely indicate the severity of bacterial infections at a single time point. In the present study, non-survivors had a relatively shorter onset of symptoms, which might indicate a lower CRP level on admission.

This study has some limitations. This is a case series study with a small number of patients, because NF is a rare disease and our inclusion criteria were restricted to peripheral NF (involvement of extremities). Central NF (involving head, neck, abdomen, and perineum) was excluded, because its etiology and surgical procedures are not similar to those of peripheral NF. NF of the head and neck often arises from an odontogenic infection with mixed aerobic and anaerobic abscesses [28, 29]. NF of the abdomen or perineum might be the result of urogenital or colorectal infections by enteric microorganisms [30]. A colostomy is usually required when treating abdominal or perineal NF [31-33]. Moreover, we did not include preexisting chronic wounds, of which the etiology might be pyomyositis or osteomyelitis. Univariate analysis rather than multivariate analysis was used to determine predictive factors for mortality, because there were only a few patients in each group. Although this study indicated that the involvement of the bilateral lower limbs and thrombocytopenia were highly associated with mortality in SMNF, additional studies are needed to confirm this.

In conclusion, the incidence of SMNF of the extremities was $8 \%$ for all subtypes of NF. Male sex, bilateral lower limb involvement, and marine Gram-negative bacteria were the most frequently found factors in SMNF. The mortality of SMNF was as high as $67 \%$, which was more frequently associated with initial thrombocytopenia and bilateral lower limb involvement. It is essential to detect a multifocal presence of NF in the extremities to justify an immediate fasciotomy and the radical removal of necrotizing tissue after prompt antibiotic therapy and sufficient resuscitation.

\section{Compliance with ethical standards}

Conflict of interest All authors declare that they have no conflicts of interest relevant to this article.

Open Access This article is distributed under the terms of the Creative Commons Attribution 4.0 International License (http://creativecommons.org/licenses/by/4.0/), which permits unrestricted use, distribution, and reproduction in any medium, provided you give appropriate credit to the original author(s) and the source, provide a link to the Creative Commons license, and indicate if changes were made.

\section{References}

1. Wilson B. Necrotizing fasciitis. Am Surg. 1952;18:416-31.

2. El-Khani U, Nehme J, Darwish A, Jamnadas-Khoda B, Scerri G, Heppell S, et al. Multifocal necrotising fasciitis: an overlooked entity? J Plast Reconstr Aesthet Surg. 2012;65:501-12. doi:10.1016/j.bjps.2011.09.001.

3. Tocco I, Lancerotto L, Pontini A, Voltan A, Azzena B. "Synchronous" multifocal necrotizing fasciitis. J Emerg Med. 2013;45:e187-91. doi:10.1016/j.jemermed.2013.05.064. 
4. Perbet S, Soummer A, Vinsonneau C, Vandebrouck A, Rackelboom T, Etienne J, et al. Multifocal community-acquired necrotizing fasciitis caused by a Panton-Valentine leukocidinproducing methicillin-sensitive Staphylococcus aureus. Infection. 2010;38:223-5. doi:10.1007/s15010-010-0002-7.

5. Park KH, Jung SI, Jung YS, Shin JH, Hwang JH. Marine bacteria as a leading cause of necrotizing fasciitis in coastal areas of South Korea. Am J Trop Med Hyg. 2009;80:646-50.

6. Hua C, Sbidian E, Hemery F, Decousser JW, Bosc R, Amathieu $\mathrm{R}$, et al. Prognostic factors in necrotizing soft-tissue infections (NSTI): a cohort study. J Am Acad Dermatol. 2015;73:1006-12. doi:10.1016/j.jaad.2015.08.054.

7. Horre R, Becker S, Marklein G, Shimada T, Stephan R, Steuer $\mathrm{K}$, et al. Necrotizing fasciitis caused by Vibrio vulnificus: first published infection acquired in Turkey is the second time a strain is isolated in Germany. Infection. 1998;26:399-401.

8. Stoneback JW, Hak DJ. Diagnosis and management of necrotizing fasciitis. Orthopedics. 2011;34:196. doi:10.3928/01477447-20110124-20.

9. Yahav D, Duskin-Bitan H, Eliakim-Raz N, Ben-Zvi H, Shaked $\mathrm{H}$, Goldberg E, et al. Monomicrobial necrotizing fasciitis in a single center: the emergence of Gram-negative bacteria as a common pathogen. Int J Infect Dis. 2014;28:13-6. doi:10.1016/j. ijid.2014.05.024.

10. H'ng MW, Chew WY, Tan BK. Necrotizing fasciitis caused by Vibrio vulnificus: a review of four cases in a Singapore tertiary hospital. J Trauma. 2005;59:482-5.

11. Tsai YH, Hsu RW, Huang KC, Chen CH, Cheng CC, Peng KT, et al. Systemic Vibrio infection presenting as necrotizing fasciitis and sepsis. A series of thirteen cases. J Bone Joint Surg Am. 2004;86:2497-502.

12. Tsai YH, Hsu RW, Huang TJ, Hsu WH, Huang KC, Li YY, et al. Necrotizing soft-tissue infections and sepsis caused by Vibrio vulnificus compared with those caused by Aeromonas species. J Bone Joint Surg Am. 2007;89:631-6. doi:10.2106/JBJS.F.00580.

13. Lee CC, Chi CH, Lee NY, Lee HC, Chen CL, Chen PL, et al. Necrotizing fasciitis in patients with liver cirrhosis: predominance of monomicrobial Gram-negative bacillary infections. Diagn Microbiol Infect Dis. 2008;62:219-25. doi:10.1016/j. diagmicrobio.2008.05.016.

14. Lee CY, Kuo LT, Peng KT, Hsu WH, Huang TW, Chou YC. Prognostic factors and monomicrobial necrotizing fasciitis: gram-positive versus gram-negative pathogens. BMC Infect Dis. 2011;11:5. doi:10.1186/1471-2334-11-5.

15. Tu GW, Hwabejire JO, Ju MJ, Yang YF, Zhang GJ, Xu JW, et al. Multidisciplinary intensive care in extensive necrotizing fasciitis. Infection. 2013;41:583-7. doi:10.1007/s15010-012-0346-2.

16. Espandar R, Sibdari SY, Rafiee E, Yazdanian S. Necrotizing fasciitis of the extremities: a prospective study. Strateg Trauma Limb Reconstr. 2011;6:121-5. doi:10.1007/s11751-011-0116-1.

17. Kalaivani V, Hiremath BV, Indumathi VA. Necrotising soft tissue infection-risk factors for mortality. J Clin Diagn Res. 2013;7:1662-5. doi:10.7860/JCDR/2013/5535.3240.

18. Adinolfi LE, Restivo L, Zampino R, Guerrera B, Lonardo A, Ruggiero $\mathrm{L}$, et al. Chronic $\mathrm{HCV}$ infection is a risk of atherosclerosis: role of $\mathrm{HCV}$ and HCV-related steatosis. Atherosclerosis. 2012;221:496-502. doi:10.1016/j. atherosclerosis.2012.01.051.

19. Liappis AP, Kan VL, Rochester CG, Simon GL. The effect of statins on mortality in patients with bacteremia. Clin Infect Dis. 2001;33:1352-7. doi:10.1086/323334.

20. Loria P, Marchesini G, Nascimbeni F, Ballestri S, Maurantonio $\mathrm{M}$, Carubbi F, et al. Cardiovascular risk, lipidemic phenotype and steatosis. A comparative analysis of cirrhotic and noncirrhotic liver disease due to varying etiology. Atherosclerosis. 2014;232:99-109. doi:10.1016/j.atherosclerosis.2013.10.030.

21. Pyrsopoulos NT, Reddy KR. Extrahepatic manifestations of chronic viral hepatitis. Curr Gastroenterol Rep. 2001;3:71-8.

22. McHenry CR, Piotrowski JJ, Petrinic D, Malangoni MA. Determinants of mortality for necrotizing soft-tissue infections. Ann Surg. 1995;221:558-63 discussion 63-5.

23. Bair MJ, Chi H, Wang WS, Hsiao YC, Chiang RA, Chang KY. Necrotizing fasciitis in southeast Taiwan: clinical features, microbiology, and prognosis. Int J Infect Dis. 2009;13:255-60. doi:10.1016/j.ijid.2008.04.015.

24. Tsai YH, Hsu RW, Huang KC, Huang TJ. Laboratory indicators for early detection and surgical treatment of vibrio necrotizing fasciitis. Clin Orthop Relat Res. 2010;468:2230-7. doi:10.1007/ s11999-010-1311-y.

25. Huang KF, Hung MH, Lin YS, Lu CL, Liu C, Chen CC, et al. Independent predictors of mortality for necrotizing fasciitis: a retrospective analysis in a single institution. J Trauma. 2011;71:467-73 discussion 73.

26. Kuo YL, Shieh SJ, Chiu HY, Lee JW. Necrotizing fasciitis caused by Vibrio vulnificus: epidemiology, clinical findings, treatment and prevention. Eur J Clin Microbiol Infect Dis. 2007;26:78592. doi:10.1007/s10096-007-0358-5.

27. Honda T, Uehara T, Matsumoto G, Arai S, Sugano M. Neutrophil left shift and white blood cell count as markers of bacterial infection. Clin Chim Acta. 2016;457:46-53. doi:10.1016/j. cca.2016.03.017.

28. Skitarelic N, Mladina R, Morovic M, Skitarelic N. Cervical necrotizing fasciitis: sources and outcomes. Infection. 2003;31:39-44. doi:10.1007/s15010-002-3057-2.

29. Whitesides L, Cotto-Cumba C, Myers RA. Cervical necrotizing fasciitis of odontogenic origin: a case report and review of 12 cases. J Oral Maxillofac Surg. 2000;58:144-51 discussion 52.

30. Czymek R, Hildebrand P, Kleemann M, Roblick U, Hoffmann $M$, Jungbluth $\mathrm{T}$, et al. New insights into the epidemiology and etiology of Fournier's gangrene: a review of 33 patients. Infection. 2009;37:306-12. doi:10.1007/s15010-008-8169-x.

31. Eke N. Fournier's gangrene: a review of 1726 cases. Br J Surg. 2000;87:718-28. doi:10.1046/j.1365-2168.2000.01497.x.

32. Gallup DG, Freedman MA, Meguiar RV, Freedman SN, Nolan TE. Necrotizing fasciitis in gynecologic and obstetric patients: a surgical emergency. Am J Obstet Gynecol. 2002;187:305-10 discussion 10-1.

33. Namkoong H, Ishii M, Koizumi M, Betsuyaku T. Fournier's gangrene: a surgical emergency. Infection. 2016;44:143-4. doi:10.1007/s15010-015-0816-4. 